Revue des études hébraïques et juives

\title{
Le Musée de la culture juive de Bratislava et les implications postcommunistes de son développement institutionnel
}

The Israeli Philosophy and the War The Museum of Jewish Culture in Bratislava and the Post-communist Implications of its Institutional Development

\section{Katalin Deme}

\section{OpenEdition \\ Journals}

Édition électronique

URL : https://journals.openedition.org/yod/682

DOI : $10.4000 /$ yod.682

ISSN : 2261-0200

Éditeur

INALCO

Édition imprimée

Date de publication : 1 janvier 2010

Pagination : $345-383$

ISBN : 978-2-85831-183-5

ISSN : 0338-9316

Référence électronique

Katalin Deme, " LE MUSÉE DE LA CULTURE JUIVE DE BRATISLAVA ET LES IMPLICATIONS

POSTCOMMUNISTES DE SON DÉVELOPPEMENT INSTITUTIONNEL », Yod [En ligne], 15 | 2010, mis en ligne le 27 octobre 2011, consulté le 08 juillet 2021. URL : http://journals.openedition.org/yod/682 ; DOI https://doi.org/10.4000/yod.682

Ce document a été généré automatiquement le 8 juillet 2021.

Yod est mis à disposition selon les termes de la Licence Creative Commons Attribution - Pas d'Utilisation Commerciale 4.0 International. 


\section{Le Musée de la culture juive de Bratislava et les implications postcommunistes de son développement institutionnel}

The Israeli Philosophy and the War The Museum of Jewish Culture in Bratislava and the Post-communist Implications of its Institutional Development

Katalin Deme

1 La création du Musée de la culture juive de Bratislava doit être considérée en relation étroite avec la réacquisition des libertés civiques en Europe Centrale consécutive aux événements de 1989 et avec la fondation de la République slovaque après son retrait de la fédération tchécoslovaque en 1993.

2 Afin de faciliter la compréhension du rôle social de cette institution, j'esquisserai dans une première partie l'arrière - plan historique et les circonstances politiques qui précédaient et justifiaient sa fondation. Dans une deuxième partie, je situerai le musée dans son environnement historique et topographique, et décrirai en détail sa politique de présentation du judaïsme en général, puis son traitement de l'image des Juifs de Slovaquie en accord avec les paradigmes de l'historiographie slovaque contemporaine. Pour finir, j'ajouterai un extrait des activités culturelles et commémoratives du musée, en les évaluant tant du point de vue des attentes des sponsors étatiques que du point de vue des représentations juives non étatiques en Slovaquie. 


\section{Les antécédents historiques et sociaux de la création du musée}

\section{Rappel historique}

3 Après la signature des «Accords de Žilina » le 6 octobre 1938, le président de la république Jozef Tiso, avec le soutien du «Parti populaire slovaque de Hlinka ${ }^{1}$ » formait le premier gouvernement autonome slovaque. Les premières mesures prises par ce nouveau gouvernement furent dirigées contre les opposants politiques et contre les Juifs.

Dès le 4 novembre 1938, deux jours après la signature du premier Arbitrage de Vienne ${ }^{2}$, plus de 7500 Juifs de nationalité hongroise ${ }^{3}$ furent déportés du territoire de la Slovaquie autonome vers la région sud du pays détachée au profit de la Hongrie ${ }^{4}$.

5 Le 14 mars 1939, l'État slovaque fut déclaré « indépendant » par la volonté d'Hitler. Le jour suivant, la Bohême-Moravie fut envahie par les troupes allemandes et elle demeura un territoire occupé jusqu'à sa libération par les troupes soviétiques en mai 1945. De cette manière controversée, la première République tchécoslovaque disparaissait de la carte de l'Europe.

Dès l'acquisition de son autonomie, l'État slovaque intensifia résolument la législation antisémite qui culmina le 9 septembre 1941 avec la codification du «Codex juif» (un pendant aux "Lois de Nuremberg»). La voie menant de la définition raciale des citoyens juifs et de la confiscation de leurs propriétés par l'État jusqu'à leur déportation du pays ne fut pas longue. Les premiers transports commencèrent en mars 1942 et se poursuivirent jusqu'en octobre $1944 ; 70000$ Juifs furent déportés du territoire de l'État slovaque vers les camps d'anéantissement et 65000 d'entre eux ne revinrent pas.

7 Il y eut cependant un événement d'importance qui suspendit provisoirement le développement fasciste de cet " état fantoche $»^{5}$, ce fut, entre août et octobre 1944, le "Soulèvement national slovaque », action militaire dirigée contre l'occupant allemand et contre l'Establishment collaborateur du pays.

8 Cet événement constitue l'un des dilemmes centraux de l'historiographie slovaque de 1948 à nos jours. Pendant le communisme, il servit à nourrir le mythe de «la libération » du pays par les Soviets sous le prétexte que c'étaient les partisans russes qui, au premier chef, avaient soutenu le soulèvement. Dans la période postcommuniste, cet événement fut interprété comme une légitimation des aspirations des Slovaques à regagner leur souveraineté nationale en interprétant le "Soulèvement » comme la manifestation d'antifascisme de la majorité des Slovaques.

9 L'interprétation morale de cet événement historique divise la société slovaque encore aujourd'hui. Les démocrates considèrent le « Soulèvement » comme une tentative pour libérer le pays de son Establishment collaborateur et refusent de voir une continuité entre l'État Slovaque fasciste et la jeune République Slovaque contemporaine. Les nationalistes voient dans le "Soulèvement" un complot communiste contre le gouvernement slovaque légal, ils vénèrent la mémoire du premier État slovaque et à partir de cette perspective, ils relativisent les crimes commis en son nom.

En ce qui concerne la responsabilité des représentants de l'État fasciste dans la déportation de la population juive de Slovaquie, il n'y avait pas eu jusqu'à aujourd'hui de débat public ouvert. Les rares discussions et polémiques menées dans les mass- 
media sur le sujet furent plutôt des manifestations isolées qui n'atteignirent pas leur but, celui d'éveiller la conscience publique. Le dilemme moral de la collaboration volontaire des Slovaques avec le régime nazi fut jusqu'en 1989 entièrement absent de l'enseignement de l'Histoire à tous les niveaux d'éducation. L'Holocauste ne fut qu'éphémèrement cité dans les manuels scolaires, sans que soit mis l'accent sur les victimes juives qui, en règle générale, étaient mentionnées avec d'autres victimes du national-socialisme en une ligne à peine.

11 La tragédie de la nation slovaque consiste dans le fait que le moment central de son histoire, notamment l'acquisition de sa souveraineté nationale, reste pour toujours associé à Hitler. Ce sujet moral douloureux de la «collaboration» causa une rupture dans la conscience historique des Slovaques qui, afin de préserver leur image nationale, continuent à éviter la confrontation avec les faits historiques peu glorieux.

Après que la Slovaquie eut obtenu son indépendance par rapport à la Fédération tchécoslovaque (le 1er janvier 1993), la situation ne changea pas dans ce domaine, au contraire. Le mythe du premier État slovaque resurgit sous une forme idéalisée et pathétique avec le consentement plus ou moins déclaré de l'Establishment politique du pays ${ }^{6}$.

13 Parmi ces conditions sociales postcommunistes, le premier musée juif de la Slovaquie indépendante cherchait sa plate-forme.

\section{La création du musée}

14 Le Musée de la culture juive de Bratislava $(\mathrm{MCJ})^{7}$ fut ouvert en 1993, quatre ans après l'écroulement des régimes communistes en Europe Centrale et en Europe de l'Est.

15 Le MCJ est une institution d'État qui fait partie du Musée National slovaque. Il reprend éthiquement l'héritage du premier Musée juif de Slovaquie, fondé en 1928 par le philanthrope hongrois Eugen Bárkány ${ }^{8}$ à Prešov (en Slovaquie orientale) et qui exista jusqu'en l'année fatale des accords de Munich ${ }^{9}$ signés les 29 et 30 septembre 1938.

\section{D’où vient la dénomination « Musée de la "culture" juive »}

16 Au début des années 90, le Musée National slovaque a conçu un programme pour maintenir et documenter les cultures des minorités du pays. Ce plan comprenait l'établissement de musées pour les Hongrois de Slovaquie, les Tchèques, les Ruthènes, les Allemands des Carpates (Karpaten-Deutsche ${ }^{10}$ ), les Juifs et les Tziganes vivant en Slovaquie.

Dans un entretien avec Roland Süssmann de la rédaction du magazine Shalom ${ }^{11}$, le directeur du MCJ, Pavol MešŤan, décrit les débuts de la formation de cette institution :

En réfléchissant sur les cadres possibles d'un musée juif slovaque, nous devions prendre en considération le niveau général du savoir et du manque de savoir relatifs au Judaïme dans la société slovaque. Commençons par établir que ce musée est une institution financée par l'État, notamment par le ministère de la Culture. La dénomination "Musée juif» pouvait évoquer une relation de propriété de la communauté juive sur le musée. Ce qui à cette époque était inopportun et même trompeur.

À propos de cet entretien, il y a lieu de préciser que le $\mathrm{MCJ}$ commença à se former en 1991 en tant que « Section de la culture juive », simple département du Musée National slovaque. Il reçut son statut de musée autonome en 1993, parallèlement avec 
l'ouverture de son exposition permanente dans un immeuble historique loué par la mairie de la ville de Bratislava.

19 Le fait que les Juifs aient été admis au programme de documentation des cultures des minorités de la Slovaquie est intéressant à différents points de vue. Tout d'abord, prêtons attention aux adeptes de cette documentation. Ce sont les minorités ethniques autochtones de différentes nationalités - à l'exception des Juifs qui, pendant toute la période de la première et de la deuxième République tchécoslovaque (de 1918 à 1938 et de 1945 à 1993), n'étaient pas recensés comme nationalité, mais comme groupe religieux. Cette forme d'encadrement social des Juifs ne changea pas non plus de caractère dans la République slovaque après 1993.

Un autre trait asymétrique dans cette cascade de minorités est que les Hongrois, les Allemands, les Tchèques, les Ruthènes et même les Tziganes ont leur propre langue, composante majeure de leur identité, tandis que nous ne pouvons pas sans réserve soutenir que les Juifs aient eu la leur d'une même façon continue (à l'exception du yiddish qui n'était pas représentatif pour tous). Il serait plus exact de dire qu'en règle générale, les Juifs parlaient la langue du vainqueur politique qui comme nous le savons, changea plusieurs fois dans cette région.

21 Le mot-clé pour résoudre ces petites contradictions conceptuelles et atteindre le paradigme idéologique souhaité, notamment l'image d'une société multiculturelle et tolérante, est justement le mot «culture ». Cette notion extensive et sensible était en outre utilisée avec prédilection et de façon emphatique dans les décennies d'avant 1989, par exemple dans les expressions: " la culture des nations, la culture du peuple, de la classe prolétarienne ", etc. Il ne faut pas oublier que s'agissant de la fondation du $\mathrm{MCJ}$, nous nous retrouvons dans une période venant quelques années à peine après le remplacement d'un système politique qui, comme tous les systèmes totalitaires, avait son propre code de langage pour désigner la réalité. La culture, dans le lexique du réalisme socialiste, était un terme unidimensionnel, immobile, sans contradictions ni tensions internes. C'était le produit d'un consensus idéologique, une forme de folklore modernisé et mis en scène pour le besoin de tous.

"Je veux voir un tableau que je comprenne, je veux écouter une chanson que je puisse siffloter [...] $»^{12}$, avait une fois déclaré, selon une anecdote, le secrétaire général du parti communiste de l'Union Soviétique, Nikita S. Khrouchtchev - ce qui n'est pas sans àpropos pour illustrer la notion de culture telle qu'elle était appréhendée à l'époque du socialisme.

\section{L'arrière-plan politique - la permanence des antagonismes}

Le sentiment enthousiaste de solidarité au sein de la société, autour des grands événements de 1989, se volatilisa rapidement et disparut sans laisser de traces vitales. Seule l'union contre l'ennemi commun avait rassemblé temporairement les différentes couches et les divers groupes de la société slovaque. Les anciens préjugés et les différentes images de l'ennemi désigné sont revenus presque simultanément avec la routine des jours et ils se sont même intensifiés à la suite de la diminution graduelle de la sécurité de l'existence et à travers la peur de la perte de l'identité nationale. Les Hongrois furent à nouveau pris pour des irrédentistes, les Tchèques pour ceux qui veulent dominer les Slovaques et les Juifs pour des cosmopolites versatiles qui se vendent, selon l'opportunité, aux intérêts hongrois, tchèques, israéliens ou mondiaux. 

déroule hors des manifestations publiques spectaculaires. L'infiltration des anciens cadres politiques dans les nouvelles structures du pouvoir est ainsi un mal inévitable qui imprègne forcément le climat de la société pendant plusieurs années. L'initiative de créer des musées pour présenter les différentes minorités autochtones vivant en Slovaquie avait déjà pris naissance pendant la première période du gouvernement de Vladimír Mečiar (27 juin 1990 - 23 avril 1991). Son cabinet se composait d'un regroupement politique de la droite populiste et nationaliste avec un nombre significatif d'anciens communistes ${ }^{15}$.

Au début des années 90, un fond financier étatique (Fond pro Slovakia) fut dévolu à la sauvegarde du patrimoine culturel de la nation slovaque et au soutien des projets culturels qui contribuaient à l'image positive de la Slovaquie aux yeux du monde extérieur. Dans la même période, les négociations entre le $\mathrm{MCJ}$ en formation et le Ministère de la Culture furent mises en train avec pour résultat que la majeure partie des projets du $\mathrm{MCJ}$ serait totalement ou partiellement subventionnée par le Ministère de la Culture ${ }^{16}$. 

de Slovaquie, aucun jusqu'à présent n'est allé au-delà de son rôle symbolique. Ces institutions sont restées plus ou moins de simples protagonistes sur un plan idéologique, sans notable signification sociale ou culturelle. Le fait que le $\mathrm{MCJ}$ ait réussi en dépit des limites étroites de ses prérogatives à dépasser sa fonction représentative et qu'il soit devenu une institution capable d'attirer l'attention internationale est dû sans conteste aux extraordinaires qualités de gestionnaire de son fondateur et directeur Pavol MešŤan.

31 Enfin, il convient de revenir à la question que nous avons déjà posée en tête de ce chapitre, à savoir, quelles étaient les vraies motivations de cette génération de politiciens opportunistes, survivants de l'ancien régime.

officiellement, le but de cette opération était de sauvegarder l'héritage multiculturel du pays comme partie intégrante du patrimoine national, et ce, bien que dans la réalité, les différentes minorités de Slovaquie fussent par définition marginalisées et méconnues. Cette contradiction apparente doit être comprise dans l'arrière-plan de la situation déstabilisée de la scène politique en Slovaquie au début des années 90, lorsqu'il était opportun de montrer une face politiquement correcte aux institutions européennes qui surveillaient le processus de démocratisation dans les sociétés postcommunistes.

33 Nous pouvons ainsi conclure que si le judaïsme slovaque, au début des années 90 , après quarante ans d'exil interne, a été sorti de l'ombre par l'État pour obtenir une plateforme officielle et se présenter en tant que culture minoritaire, c'est parce que la Slovaquie manquait alors de réelles réformes sociales et politiques et que par conséquent, elle avait besoin, d'une manière ou d'une autre, d'amender son image à l'extérieur.

\section{Le musée et les cadres de son fonctionnement}

\section{Esquisse de l'histoire des Juifs de Bratislava avant le XXe siècle ${ }^{17}$}

Le territoire de la Slovaquie d'aujourd'hui fut une partie constitutive de la Hongrie pendant presque 1000 ans, de la fin du IX siècle jusqu'à la naissance de la Tchécoslovaquie en 1918. L'histoire des Juifs de Slovaquie avant le $\mathrm{XX}^{\mathrm{e}}$ siècle s'enchevêtre avec celle de la Hongrie. C'est ainsi que les Juifs de Slovaquie furent aussi appelés Oberländer, c'est-à-dire, Juifs de la Haute-Hongrie ou de la Hongrie du Nord. Ce même contexte historique se rapporte à Bratislava qui ne devint capitale de la Slovaquie qu'à partir de 1919. Ce fait doit être pris en considération si l'on veut parler des Juifs de Bratislava avant le $\mathrm{XX}^{\mathrm{e}}$ siècle.

Les premiers Juifs sont arrivés dans la région de Bratislava probablement avec les légions romaines, vers le $\mathrm{I}^{\text {er }}$ siècle de notre ère. Les premières mentions écrites sur les Juifs de cette région ne remontent cependant qu'aux XI ${ }^{\mathrm{e}}$ et $\mathrm{XIII}^{\mathrm{e}}$ siècles. Nous savons par exemple que dans cette période, ils vivaient intra-muros, c'est-à-dire à l'intérieur de la ville, non ségrégés de la population chrétienne, qu'ils étaient surtout engagés dans le prêt de l'argent, mais qu'ils étaient aussi marchands et artisans. La première synagogue construite à Bratislava est attestée en 1335. Comme il ressort des sources médiévales, la position sociale des Juifs à Bratislava jusqu'au XVI ${ }^{\mathrm{e}}$ siècle fut plus favorable que dans 
d'autres villes européennes. Ce fait est confirmé par exemple par un édit royal promulgué en 1291 par André $\mathrm{III}^{18}$ qui leur accorda l'égalité des droits de citoyen avec les chrétiens. Les Juifs n'étaient pas non plus, contraints de porter des insignes ou des vêtements distinctifs comme leurs coreligionnaires d'autres parties de la Hongrie, sauf pendant la période allant de la fin du XV ${ }^{e}$ siècle aux années vingt du XVI ${ }^{e}$ siècle ${ }^{19}$.

Après la bataille de Mohács en $1526^{20}$, les Habsbourg arrivèrent sur le trône de Hongrie et Bratislava (alors Presburg) fut désignée comme capitale de la Hongrie occidentale et comme siège du couronnement ${ }^{21}$. La situation des Juifs changea pour le pire sous la domination des Habsbourg. Ils furent tout d'abord, expulsés en 1526 de Bratislava et de plusieurs autres villes du pays, et leurs activités économiques furent restreintes. Ceux d'entre eux qui malgré l'interdiction de résidence restèrent à Bratislava s'installèrent dans un quartier situé au-dessous du château de la ville et nommé Schlossberg. Cependant, ce ne fut qu'après 1599 , quand le château et ses rues environnantes se trouvèrent incorporés dans le domaine féodal, la manse, du comte Pállfy qui leur garantissait protection et privilèges, que les Juifs commencèrent à s'y installer en plus grand nombre. Comme témoignage d'une vie communautaire organisée «sous le château ", il faut noter la construction d'une synagogue en 1695, la fondation d'une hevra kaddish $a^{22}$ en 1696 et l'inauguration officielle du premier rabbin, Yom Tov Lippman, à la tête de la communauté en $1699^{23}$. L'activité la plus caractéristique des Juifs de Bratislava fut au XVIII ${ }^{e}$ siècle le commerce du textile ${ }^{24}$.

37 Les relations juridiques entre la famille Pállfy et les Juifs de Schlossberg (plus tard nommé aussi Zuckermandl), furent par la suite réglées dans une "Lettre protectrice " datée de 1714 qui, dans sa prise en compte équitable des droits octroyés aux Juifs, anticipait de plus d'un demi-siècle la réforme de Joseph $\mathrm{II}^{25}$. C'est en grande partie en vertu des conditions favorables garanties par les Pállfy pendant plusieurs générations et des principes adoptés également par d'autres familles de la noblesse hongroise ${ }^{26}$ que la petite enclave juive de Bratislava put se développer au cours du XVIII ${ }^{e}$ siècle jusqu'à devenir la communauté juive la plus importante de la Hongrie.

La grande époque des Juifs de Bratislava survint néanmoins plus tard, avec l'entrée en scène du rabbin orthodoxe Moses Schreiber (1762-1839) natif de Francfort-sur-le-Main (Frankfurt-am-Main), connu aussi sous le nom de Ḥatam Sofer. C'est en 1806 qu'il avait été appelé pour occuper le poste de rabbin de la communauté juive de Bratislava (à l'époque Pressburg). À partir de 1807, le rabbin Ḥatam Sofer reprit la direction de la fameuse yeshiva de Pressburg - qui existait déjà aux environs de 1700 - et qui devint sous son influence le centre d'études talmudiques le plus important après les fameuses académies de Babylonie. À travers l'autorité de Ḥatam Sofer, Bratislava devint un centre de l'orthodoxie juive pour le monde entier.

39 Parallèlement au renforcement de l'orthodoxie dû à l'influence de l'école de Ḥatam Sofer dans les régions du centre et de l'ouest de la Hongrie, les polémiques entre les orthodoxes et les réformistes - qui, de façon non officielle, se disaient «néologues »gagnèrent en intensité. Le schisme à l'intérieur de la communauté juive de Hongrie fut à l'origine de la convocation en 1868 par le ministre hongrois de l'Éducation et des Affaires religieuses József Eötvös à Buda, du «Congrès général hongrois ». La mission du congrès était de définir la base de l'organisation autonome des communautés juives de Hongrie (selon les critères des orthodoxes ou des défenseurs de la réforme) et de régler les questions concernant la modernisation du système éducatif juif, entre autres, la décision de renoncer à l'hébreu et au yiddish comme langues d'instruction. Comme 
prévu, le congrès approuva les propositions de l'aile réformiste, ce qui eut pour conséquence immédiate, en signe de protestation, le retrait des délégués orthodoxes. La communauté juive de Slovaquie se disloqua ensuite en trois fractions : les néologues, les orthodoxes et les status quo ante (ceux qui décidèrent de garder leur statut juridique d'avant le congrès et de ne s'allier à aucune des fractions opposées).

Après le schisme, Bratislava continua d'être la citadelle de l'orthodoxie et le resta jusqu'aux abords de la Deuxième Guerre mondiale où les antagonismes entre tradition et modernité furent dissous par la menace commune qui mit en danger existentiel toute la communauté.

\section{Le contexte historique de la localisation du MCJ sur le plan topographique de la ville de Bratislava}

41 L'exposition permanente du MCJ est située dans un immeuble historique, dans la curie Zsigray, construite fin $\mathrm{XVII}^{\mathrm{e}}$ siècle - début XVIII ${ }^{\mathrm{e}}$ siècle, dans les vestiges de l'ancien quartier juif. Ce bâtiment est l'un des derniers témoins architecturaux de ce quartier situé au-dessous du château de Bratislava. Le quartier juif, appelé aussi Zuckermandl, fut quasiment détruit entre 1967 et 1972 pendant la construction du deuxième pont sur le Danube (Nový Most - le Pont Neuf) et de ses routes d'accès. Des rues entières, composées de petites perles d'architecture de style Renaissance et baroque disparurent, y compris une imposante synagogue néologue ${ }^{27}$ construite en 1899. Cette démarche de barbarie et d'irrévérence envers le passé prenait sa source dans un projet de dépossession graduelle d'une ville de sa propre histoire.

Bratislava est devenue capitale de la Slovaquie en 1919, dans le cadre de la République tchécoslovaque. À cette période, $33 \%$ de la population de cette ville était slovaque ; la majorité, $36 \%$, se disait allemande et le reste, $29 \%$, était constitué de Hongrois. En ce qui concerne l'appartenance nationale des Juifs, elle changeait de proportions au gré des circonstances historiques. Il est d'autant plus difficile de délimiter cette appartenance à un groupe ethnique qu'une partie significative de Juifs religieux se laissait enregistrer en tant qu'adhérents à la confession mosaïque (ils représentaient $12 \%$ de la population de Bratislava) ${ }^{28}$.

Non sans à-propos, l'historien Pavel Dvořák décrit l'esprit inclément de cette époque :

D'un côté se tenaient les traditions, et de l'autre côté l'avenir. Au nom de cet "AVENIR", écrit en grands caractères, disparurent les palais patriciens et grandirent les complexes de style fonctionnaliste. En 1974, la construction du nouveau pont fut terminée; le quartier juif dont il ne restait que quelques bâtiments, fut entièrement retranché de la ville même, perdit sa continuité naturelle et devint un univers en soi. Une unité architectonique formée au fil des siècles s'était décomposée et un complexe sans relations historiques et sans rapport au reste de la ville était né29.

Cette description est d'une valeur presque allégorique pour l'histoire des Juifs de Bratislava et pour la position sociale du musée juif même. Trois décennies après l'anéantissement de la communauté juive de Bratislava au nom d'une nouvelle idéologie totalitaire, même le site de cette communauté de jadis devait disparaître. Ce projet d'assainissement architectural d'un ancien quartier situé sous le château de Bratislava faisait partie d'un processus prémédité de déracinement historique de la ville et de ses habitants. 
45 La circonstance qui veut que le MCJ occupe un des derniers immeubles historiques subsistant après la destruction du quartier juif de Bratislava, contextualise perceptiblement le musée. Il se transforme ainsi d'espace d'exposition conventionnel en « témoin du temps » qui transmet sa propre histoire.

\section{Bref parcours de l'exposition}

Dans son essai sur les diverses approches muséologiques permettant d'exposer un objet et son contexte, Stephen Greenblatt ${ }^{30}$ distingue entre deux modèles principaux: le premier met l'accent sur la valeur esthétique de l'objet en suscitant chez le visiteur un sentiment d'étonnement, le second se focalise sur le contexte de l'objet et vise à provoquer une résonance intellectuelle.

47 Comme exemple pour le deuxième modèle de représentation du passé, évoquant une résonance plus intériorisée, Greenblatt se réfère au Musée juif de Prague. Pour comprendre la conception sur laquelle s'appuie le MCJ (qui, au demeurant, est historiquement lié au Musée juif de Prague), nous allons suivre les points culminants de son exposition permanente.

48 Signalons tout d'abord que l'exposition permanente du MCJ est axée sur le côté religieux du Judaïsme et sur les aspects culturels issus de la religion. Elle se déploie sur cinq salles en enfilade, situées au premier étage d'une curie Renaissance, complétées au rez-de-chaussée par un petit mausolée consacré à la mémoire du grand rabbin orthodoxe Ḥatam Sofer ${ }^{31}$, fondateur de la fameuse «Yeshivat-Pressburg $»^{32}$. Au sous-sol se trouve une salle dédiée aux expositions temporaires et aux diverses manifestations culturelles.

49 La première salle d'exposition relate l'histoire du judaïsme slovaque depuis l'époque romaine jusqu'après la Shoah. Les deux salles suivantes proposent une approche plus ethnologique puisqu'elles sont consacrées aux fêtes juives et au cycle de la vie de la circoncision à la mort. Le point culminant de ce parcours est une petite synagogue reconstituée pour les visiteurs non initiés au judaïsme. Suit une pièce consacrée à l'imprimerie juive en Slovaquie ${ }^{33}$ à travers les siècles et au cycle de l'éducation juive traditionnelle. La visite se termine dans une salle consacrée à la Shoah, là se trouve un mémorial représentant les diverses couches de la mémoire sociale au moyen d'une succession de lignes ondulées, dessinées sur des panneaux en verre placés les uns derrière les autres, créant ainsi l'illusion de l'espace infini du temps.

Le long des murs, il y a des photos de résistants juifs ainsi qu'une petite vitrine consacrée aux Slovaques ayant obtenu La Médaille des Justes de Yad Vashem en raison de leurs actes de courage pendant la Shoah. À côté de cette vitrine, sur une plaque de marbre noir, sont gravés les noms des rabbins de diverses communautés juives de Slovaquie; chacun représente une communauté détruite. Dans cette pièce, le moment de confrontation psychologiquement calculé survient lorsque le visiteur constate l'affichage d'un extrait de facture des Chemins de fer slovaques en paiement d'une somme de 500 Reichsmark aux autorités allemandes pour chaque Juif déporté de Slovaquie (notons que cette somme fictive fut justifiée comme redevance pour «logement, nourriture, habillement et reconversion $»^{34}$ des déportés). Pendant que le visiteur contemple les installations, la voix enregistrée d'Eliáš Katz, dernier rabbin de Slovaquie avant le tournant de 1989 (il occupa son poste entre 1945 et 1968), chante en boucle « El male rahamim ». Pour sortir du musée, le visiteur doit refaire son parcours en 
sens inverse, repassant par les pièces déjà traversées; il voit de nouveau les images pleines de vitalité des traditions et des rites. Cette rétrospection spontanée l'aide à se délivrer de l'atmosphère oppressante de la dernière pièce et à ne pas quitter le musée en associant le Judaïsme uniquement avec la tragédie de la Shoah.

En revenant sur les deux principes de représentation muséographique formulés par $\mathrm{S}$. Greenblatt, nous pouvons constater que l'exposition permanente du MCJ - tout comme les complexes d'exposition du Musée juif de Prague - est plus proche du modèle qui met l'accent sur le contexte des objets installés plutôt que sur leur valeur esthétique.

Dans son enquête intéressante sur le judaïsme slovaque contemporain, Roland S. Süssmann décrit ainsi l'exposition permanente du MCJ : «C'est une exposition-dépôt contenant toutes sortes d'objets cultuels sans grande signification muséographique [...] ». Un peu plus tard il parle «des magnifiques boîtes à bessamim ${ }^{35}$ », mais regrettablement il ne va pas jusqu'à mentionner les quelques rares objets présents ayant une valeur muséographique et ethnographique exceptionnelle (comme par exemple, deux cruches rituelles au décor Habaner du XVIII siècle, appartenant originairement à la hevra kaddisha de Senica). En ce qui concerne la conception de l'exposition et les textes sur les panneaux et les vitrines en général, il parle "d'une conception didactique et concise où chaque objet est décrit de manière précise et détaillée $»^{36}$.

Cette évaluation fluctue ainsi entre le cadre de l'étonnement et celui de la résonance, en insistant plutôt sur cette dernière. Essayons d'indiquer les raisons qui sous-tendent ses principaux arguments : Le fait que le MCJ à Bratislava, comparé à d'autres musées juifs d'Europe Centrale ne dispose pas d'un aussi grand nombre d'objets cultuels ayant qualité d'objets d'art, est en rapport étroit avec la situation socio-économique du Judaïsme slovaque qui, jusqu'à la création de la première République Tchécoslovaque (1918-1938), ne changea pas notablement son profil. En 1930 encore, plus de $50 \%$ des Juifs de Slovaquie vivaient dans des villes de moins de 5000 habitants ${ }^{37}$; la majorité d'entre eux parlait le yiddish et vivait souvent dans la pauvreté et l'isolement par rapport à la société environnante. À cause de sa tendance marquée vers l'orthodoxie conservatrice, cette communauté fut à peine influencée par l'émancipation et la modernité qui, en revanche, avaient radicalement changé la position sociale des coreligionnaires des autres parties de l'Empire austro-hongrois de jadis.

54 Toute la conception de l'exposition est construite autour de cette image conservatrice du judaïsme. Elle se focalise consciemment sur la simplicité et l'authenticité de représentation qui est en fait sa marque de qualité particulière. En prenant en considération le fait que la majorité des visiteurs du MCJ sont des écoliers et des lycéens slovaques non initiés au judaïsme, la démarche méthodologique de ses concepteurs était, non de mettre en relief l'esprit et la richesse des traditions relatives au judaïsme, mais de montrer la vie quotidienne comprise à travers ses traditions et d'essayer ainsi de donner un visage humain à l'inconnu qui nourrit les préjugés.

\section{Mise en scène de la mémoire sociale et de ses oublis}

55 Une nécessité incontournable dans les relations entre les diverses minorités (qu'elles soient nationales, religieuses ou sociales) et les pouvoirs politiques qui assurent leur existence est la mise en évidence de leur loyauté envers l'État qui les abrite. Une forme de démonstration de la loyauté civique est l'identification de soi avec les mythes et les 
tabous historiques de la société ambiante. Le MCJ, en tant qu'institution d'État financée par les subventions du Ministère de la Culture, doit nécessairement aussi accepter certaines doctrines idéologiques officiellement et publiquement reconnues. Cette posture d'équilibre entre l'éthique et la tactique se reflète évidemment dans la conception de son exposition permanente.

\section{Un mythe}

56

donné la voie troublée vers la souveraineté nationale des Slovaques à travers la domination millénaire hongroise puis à travers l'inégalité de leur statut dans les deux périodes de la Fédération tchécoslovaque, nous comprenons peut-être l'emphase avec laquelle on se réfère dans ce pays à l'autodétermination politique en tant que telle. Néanmoins, il aurait été difficile pour les concepteurs du MCJ de s'identifier avec la continuité de la souveraineté nationale slovaque en tant que principe, compte tenu du destin des 70000 Juifs déportés du premier État slovaque entre mars 1942 et octobre $1944^{38}$, et de l'antisémitisme historiquement enraciné dans les mentalités du pays. Pour résoudre cette contradiction, il fallait donc exalter un événement particulier de l'histoire de la Slovaquie lié aux aspirations nationales, mais ayant aussi un caractère de manifestation démocratique qui puisse servir de point d'identification commun à toute la société. slovaque (SNS) qui eut lieu dans la région montagneuse de la Slovaquie centrale, autour de la ville de Bánská Bystrica, entre août et octobre 1944. C'était une révolte semimilitaire, semi-partisane contre l'occupant allemand; ce fut au fond, une tentative stratégique pour sortir de la fausse alliance hitlérienne avant la défaite certaine. Les intérêts du gouvernement en exil d'Eduard Beneš ${ }^{39}$ à Londres, ainsi que ceux des Soviétiques et des Alliés, désireux d'assurer leurs sphères d'influence après la guerre, ont joué un rôle important dans le déclenchement et dans le soutien militaire du Soulèvement. Pendant le Soulèvement, les partisans réussirent à ouvrir les portes de deux camps de travaux forcés en Slovaquie occidentale, à Sereň et à Nováky (ces centres existaient depuis 1939 et servirent plus tard de lieux de déportations). À peu près 2000 Juifs ainsi libérés se rallièrent aux combats contre les occupants nazis et contre l'Établissement fasciste de l'État slovaque ${ }^{40}$. Il n'est pas sans importance de noter qu'après que le Soulèvement fut réprimé du fait de la prépondérance des troupes allemandes, Jozef Tiso, président fondateur de l'État slovaque et prêtre catholique, célébra une messe solennelle, décora les membres des SS et remercia publiquement Hitler pour son intervention qui contribua à étouffer les forces antifascistes en Slovaquie ${ }^{41}$.

L'évaluation historique du SNS polarise encore aujourd'hui la société slovaque. Une fraction de celle-ci, particulièrement les électeurs du Parti national slovaque et les cercles patriotiques des dissidents slovaques à l'étranger, condamne le Soulèvement, le considérant comme un acte de trahison contre la souveraineté nationale, immuable des Slovaques. Néanmoins, grâce à son caractère antifasciste, cet événement constitue pour la majorité de la société un mythe fondateur qui veut prouver qu'il n'y a pas de continuité ni juridique ni éthique entre l'État slovaque fasciste et la République slovaque d'aujourd'hui. Cette dernière conclusion n'est quand même pas sans contradictions, car les idéologues fondateurs du deuxième État slovaque souverain étaient justement les admirateurs mal dissimulés de l'État slovaque fasciste. 
59 En ce qui concerne le MCJ, il se heurte dans ce dilemme à la loyauté citoyenne juive, loyauté qui doit être inattaquable et convenir à toute version officielle même dans des circonstances historiques controversées. Conformément à cette attitude circonspecte, son exposition permanente relate la chronologie de la présence des Juifs sur le territoire de la Slovaquie, avec, sous-entendue, l'emphase mise sur un patrimoine historique commun. En arrivant à la période de la Shoah, lorsque toute démonstration de la loyauté citoyenne juive s'est révélée vaine, cette version officielle essaye d'établir un contrepoids moral en s'identifiant avec les forces antifascistes slovaques à travers la participation des Juifs dans le soulèvement militaire contre les nazis. À ce Soulèvement national slovaque, participaient aussi des soldats tchèques, russes, anglais et français, sans qui cette révolte héroïque aurait été immédiatement étouffée. Ce fait reste consciemment omis de la documentation de l'exposition pour ne pas heurter la version officielle de cet événement historique.

\section{Un tabou}

60 Le 15 mai 1942, le Parlement slovaque promulguait une loi de déportation commençant par ces mots: «Les Juifs peuvent être déportés du territoire de la République slovaque... $»^{42}$. Le comte János Esterházy, dirigeant du Parti hongrois unifiée ${ }^{43}$, fut seul parmi les 80 députés à refuser de voter la déportation de la population juive. Sa prise de parole parlementaire commençait ainsi :

Il est honteux qu'un gouvernement dont le président et dont le premier ministre se considèrent comme de bons catholiques soit prêts à laisser déporter sa population juive dans les camps de concentration hitlériens [...]. Moi, en tant que hongrois et chrétien, je considère cette motion comme impie et inhumaine ${ }^{44}$.

61 L'historiographie slovaque évalue cette intervention comme une action calculée pouvant servir d'alibi, en argumentant que pendant sa carrière politique, Esterházy avait plusieurs fois exprimé une opinion négative à l'encontre des Juifs (par ex., le 8 octobre 1940, lors d'une session du Parlement slovaque, il avait dit: "La nation hongroise a souffert pendant des siècles à cause des Juifs [...] $»)^{45}$, soutenant ainsi personnellement leur isolement et leur discrimination.

62 János Esterházy était le porte-parole de la minorité hongroise de Tchécoslovaquie depuis les années 30. Après l'arbitrage de Vienne en novembre 1938, il s'engagea pour les droits des 67000 Hongrois restés dans la Slovaquie autonome (la majorité, soit environ 505808 Hongrois, fut transférée en même temps que les territoires détachés de la Hongrie $)^{46}$. Dans son programme politique, Esterházy soutenait la coexistence pacifique des Hongrois avec les Slovaques et militait contre le détachement territorial. Il revendiquait le droit à l'autodétermination des Hongrois, à un domaine national, religieux et culturel, et plaidait en faveur de l'autonomie de la Slovaquie. Il était en contact avec les participants du soulèvement contre les occupants allemands, il se chargea de procurer de faux passeports aux réfugiés juifs comme aux ressortissants tchèques ou slovaques, et il les aida à s'échapper à travers la Hongrie. En 1945, il fut arrêté par la police secrète slovaque à Bratislava, puis condamné au bannissement dans les goulags soviétiques. En 1947, il fut condamné par contumace à la peine de mort pour haute trahison. Ce verdict fut commué plus tard en réclusion perpétuelle. En 1949 il revint en Tchécoslovaquie, gravement malade et affaibli, mais il ne recouvra pas sa liberté. Il décéda après 12 ans de détention, le 8 mars 1957, dans les murs de la prison 
de Mírov en Moravie. La restitution de sa dépouille mortelle à sa famille et un enterrement digne ne sont pas autorisés jusqu'à ce jour ${ }^{47}$.

Esterházy était-il un revanchard territorial hongrois et un traître fasciste comme on l'en accuse, ou bien un homme resté fidèle à ses idéaux humanistes même dans les conditions les plus inhumaines? Moshé Beisky, président du Comité du souvenir des Martyrs et des Justes de l'Holocauste à Yad Vashem, le caractérise ainsi :

"Le nom de János Esterházy, sa fermeté courageuse et son sens de l'équité demeurent pour toujours dans la mémoire des Juifs de Slovaquie et des Juifs du monde entier ». (Jérusalem, 13 janvier 1994) ${ }^{48}$.

Selon Ján Čarnogurský, fondateur du Parti démocrate-chrétien slovaque, Premier ministre entre 1991 et 1992, puis ministre de la Justice entre 1998 et 2000, «János Esterházy fut injustement condamné à mort en 1947, même la loi qui était en vigueur alors fut bafouée. Malgré tout, notre régime légal ne permet pas sa réhabilitation juridique » (Bratislava, 29 mars 2001) ${ }^{49}$.

65 Notons que Martin Sokol, président de la Chambre des députés du Parlement slovaque pendant toute la période des déportations, ne fut, après la guerre, condamné qu'à cinq ans de prison. Par ailleurs, le portrait de Andrej Hlinka, fondateur du Parti du Peuple slovaque, parti antisémite responsable d'exactions graves contre les Juifs, se trouve sur les marques d'honneur de l'État, son effigie figure sur les billets de 1000 couronnes slovaques et des rues portent son nom. Les voies de la justice sont impénétrables.

János Esterházy fut réhabilité le 21 janvier 1993 en Russie, sa réhabilitation dans son pays natal se fait encore attendre aujourd'hui ${ }^{50}$.

Que le Musée juif ne s'engage pas dans ce dilemme, n'a rien d'étonnant. L'identification des Juifs avec les Hongrois a de tristes antécédents en Slovaquie. Après 1945, les Juifs furent persécutés et discriminés en tant que Hongrois et jusqu'à la fin de l'année 1948, tous les Juifs de nationalité non slave (les Juifs allemands et hongrois) durent quitter le pays, pour « calmer l'opinion publique et paralyser les humeurs antisémites $»^{51}$. Dans la période allant de 1945 à 1948, 17270 des 25000 Juifs revenus des camps de concentration, quittèrent la Slovaquie. Être Hongrois, c'était être un ennemi interne. La peur qu'ont les Juifs d'être l'objet d'une double discrimination est encore aujourd'hui justifiée.

\section{Comment les Juifs de Slovaquie sont devenus Juifs slovaques (du point de vue général et à travers la prise en compte de l'exposition permanente du MCJ)}

Afin de nous tenir plus proche des cadres de fonctionnements immédiats du MCJ, nous nous limiterons dans notre analyse à l'échantillon de la composition ethnique de Bratislava, qui, sans être entièrement représentatif de tout le pays, reflète un condensé des tendances de la même problématique et met plus en relief le processus d'urbanisation et d'assimilation culturelle des Juifs de Slovaquie.

Le 4 février 1919, le siège du premier gouvernement slovaque fut transféré à Bratislava, officiellement déclarée dès le 18 janvier de la même année, capitale de la Slovaquie ${ }^{52}$. À l'occasion de cet événement historique, le chef du cabinet slovaque Vavro Šrobár s'exprima ainsi :

Dans le nouvel État, Bratislava est occupée par des Slovaques; de ce fait, le malheur qui, il y a mille ans, avait atteint la Grande Moravie après la mort du roi Svätopluk a été réparé53 [...]. Les Slovaques sont redevenus les maîtres de leur propre destin et, là où les ancêtres avaient 
essuyé une défaite, leurs descendants hissent victorieusement le drapeau de la liberté

slovaque $^{54}$. Allemands et des Hongrois commença par une « appropriation linguistique » : les noms de Pressburg/Pozsony/Prešporok sont remplacés par celui de Bratislava ${ }^{55}$. Cette dénomination entra officiellement en vigueur à partir de mars 1919. En ce qui concerne le lien de continuité historique entre «Bratislava » et le Royaume de Grande Moravie, il s'agit purement et simplement d'un mythe qui sert à légitimer la slavisation de cette ville par le nouveau conquérant politique.

Pressburg ${ }^{56}$, ville située dans l'Empire des Habsbourg, à $60 \mathrm{~km}$ à l'est de Vienne, était avant la ratification de «l'Entente austro-hongroise » de $1867^{57}$ et sa « magyarisation » consécutive par les autorités hongroises, une ville majoritairement allemande. Cette configuration ethnique évolua jusqu'à ce que, et pour la première fois, la proportion des Allemands et des Hongrois s'équilibre dans la population, ce que fit apparaître le recensement de $1910^{58}$. En ce qui concerne le nombre de Juifs à Pressburg dans la même période (entre 1900 et 1910), il variait autour de $10 \%$ de la population totale ${ }^{59}$. Ce pourcentage ne représente néanmoins que le nombre de Juifs qui s'étaient fait enregistrer dans cette période en tant qu'adhérents à la religion israélite (sans doute leur majorité), mais n'englobe pas ceux qui s'étaient déclarés en tant qu'Allemands ou Hongrois.

Après la dissolution de l'Empire austro-hongrois en 1918 et son remplacement par de petits États nationaux, parmi lesquels la Tchécoslovaquie, le statut national de Pressburg changea de nouveau. Ce processus politique fut introduit par la renomination de Pressburg en Bratislava - qui devint capitale de la Slovaquie dans le cadre de la Tchécoslovaquie -, et par la promotion conséquente d'un accroissement de l'élément slave dans la population. À Bratislava, entité idéologique nouvellement conçue, où la population était inextricablement entrecroisée par des mariages mixtes et où le bi - ou trilinguisme était un phénomène tout naturel, l'homogénéisation ethnique de la population devint une tâche complexe et de longue haleine. Les nouveaux pouvoirs publics se trouvaient soudain face au problème de savoir comment différencier les Allemands et les Juifs de nationalité allemande, les Hongrois et les Juifs de nationalité hongroise, les Slovaques et les Slovaques de nationalité allemande ou hongroise, etc. Comme premier pas pour mettre fin à cette situation embrouillée et pour rassembler la population sous un même drapeau, fut introduite la catégorie statistique de nationalité tchécoslovaque qui, lors du recensement de la population en 1919, englobait $30 \%$ environ des habitants de Bratislava ${ }^{60}$.

La conscience nationale des Juifs de Bratislava fut dans les premières années d'existence de la Tchécoslovaquie encore fortement influencée par leur loyauté envers la Hongrie, mais quand il apparut clairement que la Tchécoslovaquie démocratique de Masaryk garantissait également aux Juifs le libre exercice de leur foi et n'exigeait pas de renoncement à leur identité, ceux-ci devinrent de loyaux citoyens dans la nouvelle république. Dès 1921, les Juifs de Tchécoslovaquie eurent la possibilité de se déclarer de nationalité juive. Cette légitimation par l'État de leur statut de citoyen à part entière renforça encore plus leur loyauté envers le pays.

74 Il est intéressant de noter que lors du recensement de 1921, de tous les Juifs de Bratislava (soit $11,77 \%$ de la population de cette ville) seulement $34,25 \%$ se déclarèrent 
de nationalité juive ${ }^{61}$. Leur appartenance nationale oscillait en majeure partie entre les nationalités tchécoslovaque, hongroise et allemande.

Lors du recensement suivant, en 1927, la proportion des personnes enregistrées sous la catégorie de nationalité juive par rapport au nombre total des Juifs (soit 9,5\% de la population de la ville) s'accrut, passant à $39,89 \%^{62}$. Ce renforcement modéré de la conscience nationale des Juifs de Bratislava était en partie dû à l'influence idéologique du mouvement sioniste qui gagnait en Slovaquie de plus en plus de sympathie dans les cercles de la jeune génération.

En 1930, les Juifs représentaient $12 \%$ de la population de Bratislava : $37 \%$ d'entre eux se déclarèrent de nationalité juive ${ }^{63}, 42 \%$ de nationalité slovaque, $9 \%$ de nationalité hongroise ${ }^{64}$. Nous voyons que dans la période allant de 1921 à 1930 l'attachement des Juifs de Bratislava à la nationalité juive varia sans écarts marquants, autour de $35 \%$ à $40 \%$, tandis que leur adhésion aux nationalités allemande, hongroise, tchécoslovaque ou slovaque, fut beaucoup plus fluctuante.

77 La liberté des Juifs de définir et de redéfinir leur identité prit fin lors du recensement de la population du 15 décembre 1940, quand tous les Juifs de Slovaquie sans exception furent contraints par les autorités publiques de se déclarer de nationalité juive ${ }^{65}$. Cette mesure administrative préparait le terrain à la définition raciale des Juifs ; elle culmina le 9 septembre 1941 avec la codification de la législation antisémite du "Codex juif » ${ }^{66}$ et conduisit à partir d'octobre 1942 à leurs déportations du pays. En octobre 1941, les Juifs furent expulsés de Bratislava ${ }^{67}$. La population expulsée prit le chemin des villes de province ou celui des camps et des centres de travail forcé.

Les circonstances extrêmes du recensement de 1940 avaient de façon préméditée modifié l'évolution démographique et nationale naturelle de la communauté juive de Slovaquie de sorte que les données statistiques recueillies n'en reflétaient plus la structure historique. Par conséquent nous renonçons à nous référer aux résultats de ce recensement.

79 Après la Deuxième Guerre mondiale, la population juive de Tchécoslovaquie qui en 1930 avait compté 138000 personnes s'était réduite à quelques milliers d'âmes. Entre 1945 et 1948, en conséquence de la juridiction communiste, les plus grandes minorités nationales de Tchécoslovaquie, les Allemands et les Hongrois, furent expulsées en masse du pays. Appartenir à ces nationalités devenait désormais inopportun et même risqué. Cet état de fait se reflétait également dans la recomposition ethnique de Bratislava, où, lors du recensement de 1950, 90,2\% des habitants se déclarèrent de nationalité slovaque ${ }^{68}$. Ce pourcentage en faveur de la nationalité slovaque se stabilisa pendant la période de la République tchécoslovaque socialiste et représenta alors, à quelques faibles écarts près, l'image ethnique de la ville. Le processus idéologique qui avait commencé en 1919 par la slavisation du nom d'une ville historiquement multiethnique finissait 70 ans plus tard, par sa transformation en une ville presque entièrement uniethnique. Bien que depuis 1989 il y ait eu à Bratislava un certain réveil des ambiances multiculturelles, sans pluralisme réel en arrière-fond, celles-ci s'étouffèrent très tôt dans des clichés vides de contenu ${ }^{69}$.

80 L'exposition du MCJ ne prend nullement en considération la pluralité des identités juives dans le contexte de la Pressburg/Bratislava décrite ci-dessus. Elle ne mentionne pas davantage la diversité des langues parlées par les Juifs de cette ville, pas même le yiddish qui, d'ailleurs, correspondrait bien au contexte religieux dans le cadre duquel le musée présente le judaïsme slovaque. C'est en adoptant la norme officielle de 
l'homogénéité ethnique du pays que l'exposition du MCJ a converti les Juifs de Slovaquie en Juifs slovaques.

81 Comme nous l'avons démontré, le rôle du MCJ dans la réévaluation des sujets historiques ou sociaux tabouisés est très restreint. Sans concurrent institutionnel direct et avec pour unique partenaire de négociation le Ministère de la Culture - qui est en même temps son tuteur - le MCJ a une politique de médiatisation figée, sans moyens pour un renouvellement. De ce fait, au lieu de jouer le rôle de régulateur entre les différents niveaux de mémoire de la société, le MCJ doit osciller entre les différents niveaux d'oublis sociaux, et ce, sous la supervision de l'État.

Pour conclure citons Pavol MešŤan, qui dans un entretien pour le magazine Shalom s'expliquait ainsi au sujet de sa tâche professionnelle :

«Pour moi, il s'agit avant tout de lutter contre l'ignorance qui provoque et entretient l'antisémitisme $»^{70}$. Il dépend du développement démocratique de la société slovaque que cette tâche soit, dans l'avenir, poursuivie en arrière-plan.

\section{Expositions et monuments érigés après 1989 et en rapport avec l'histoire du judaïsme slovaque}

\section{Les diverses expositions du culte synagogal et le premier Musée de I'Holocauste en Slovaquie} sous le nom "Synagoga Slovaca », 107 synagogues et lieux de culte ont été recensés à ce jour. Il s'agit d'une opération conjointe du Musée national, du Musée de la culture juive, de l'Institut des études juives de l'Université Comenius et de la Faculté d'architecture de l'Université technique de Bratislava. L'organisation soumet régulièrement les résultats de ses recherches au Ministère de la Culture afin qu'il débloque des fonds pour la restauration des synagogues ${ }^{71}$. Dans plusieurs synagogues et lieux de culte restaurés, des expositions axées sur la religion juive ont été installées : dans les villes de Prešov, située en Slovaquie orientale, de Trnava, située en Slovaquie de l'ouest et de Žilina, située en Slovaquie centrale. Ces expositions dépendent administrativement du MCJ de Bratislava. de Slovaquie occidentale, a été ouvert en octobre 2005. L'établissement d'un Musée de l'Holocauste dans ce lieu avait originairement pour but de sauver l'imposante synagogue de Nitra, condamnée au délabrement consécutif aux outrages du temps. Il faut savoir que la communauté juive de Nitra était l'une des plus anciennes sur le territoire de la Slovaquie. Elle avait une synagogue néologue, construite en 1911 sur une base de $620 \mathrm{~m}^{2}$. En 1930, à Nitra vivaient 3809 Juifs. Presque personne n'a survécu aux déportations ${ }^{72}$.

Parallèlement à l'initiative de sauver la synagogue de Nitra, il y avait aussi une autre raison stratégique pour placer un musée de l'Holocauste justement dans cette ville. Nitra est un siège épiscopal, donc une ville fondamentalement catholique et c'est également la citadelle du Parti national Slovaque, parti nationaliste extrémiste. Cette combinaison de bigoterie religieuse et de nationalisme radical produit un terreau idéal pour que se développe une mentalité xénophobe, méfiante envers tout ce qui diffère 
d'une façon ou d'une autre du système de valeurs de la majorité. C'est bien dans cette région que le mythe de l'État slovaque fasciste est le plus vénéré. L'implantation d'un musée de l'Holocauste au cœur de cette ville signifie une confrontation inévitable de la population locale et régionale avec les faits historiques qui s'opposent à l'image idéalisée du passé, tendancieusement diffusée par certaines autorités de l'église et certaines fractions politiques.

Nous devons ajouter que la reconversion de ces anciens lieux de culte en centres éducatifs et en lieux de rencontres «intrasociales» n'aurait pas été possible sans l'initiative et la coordination professionnelle du MCJ.

\section{Mémoriaux pour une communauté disparue, établis avant et après 1989}

La commémoration officielle de l'Holocauste par l'État communiste entre 1945 et 1989 fut incluse parmi les autres manifestations antifascistes et prosoviétiques, pour légitimer les structures du pouvoir politique en place. Les mémoriaux de l'Holocauste élevés en Slovaquie ${ }^{73}$ après 1945 clamaient dans le même style fonctionnaliste des innombrables mémoriaux de la libération du pays par l'Armée rouge, la puissance du nouveau conquérant et la justesse universelle du nouvel ordre social. Les textes sur les austères stèles de marbre se limitaient à des inscriptions laconiques de deux types principaux : «À nos martyrs » ou "Zakhor!» (Souviens-toi !) sans désigner le contexte historique de ce dont on était appelé à se souvenir (par ex. la responsabilité de l'État slovaque dans l'organisation des déportations). La rhétorique introvertie de ces inscriptions s'adressait en fait aux Juifs mêmes, car la société majoritaire ne se souvenait plus du contexte de ces "mément " " gravés dans le marbre, étant donné qu'elle avait été systématiquement instruite pour oublier le passé. Concernant l'emploi erroné de la notion de "martyr ", c'est-à-dire de celui qui se sacrifie volontairement (ce qui n'est pas du tout valable pour les Juifs ayant péri dans les camps d'annihilation), c'est un emprunt abusif de la rhétorique officielle qui désigne ainsi ceux tombés dans la lutte pour la libération de la Patrie et qui, par conséquent, tente de classer les Juifs dans une catégorie plus large englobant toutes les «victimes du fascisme ». Finalement, si nous réexaminons l'expression "À nos martyrs » comme entière, nous pouvons nous demander à qui la forme possessive "nos » se rapporte en réalité. La réponse à cette question est que, dépourvus de l'attribut officiel trompeur qui transforme les victimes en "martyrs", les centaines de milliers de morts n'appartenaient plus à la société entière et de ce fait, n'étaient commémorés que dans les cadres fermés des communautés juives. Le cercle de la mémoire sociale officielle se refermait ainsi sans atteindre les sphères de mémoire de la société.

La politique de commémoration de l'Holocauste après 1989 perdit, dans la Slovaquie postcommuniste, son contenu idéologique unifié et fut déléguée à divers groupes d'intérêt, souvent opposés. Nous nous concentrons dans ce qui suit sur la démarche commémorative de deux fractions représentatives du même groupe, celle du Musée juif sous la tutelle de l'État et celle de la communauté juive de Bratislava, soutenue et supervisée par divers groupes d'influence de l'Orthodoxie juive internationale.

90 L'initiative de placer un mémorial de l'Holocauste en plein centre de Bratislava, aux abords de l'ancien ghetto juif démoli pendant le communisme, rencontra une résistance tenace de la part de la mairie de la ville, traditionnellement sous l'influence des démocrates-chrétiens très conservateurs, ayant une relation ambivalente quant à 
l'évaluation historique de la période de l'état fasciste de Tiso. Étant donné que l'élément architectural le plus élevé du centre historique de Bratislava est aujourd'hui le dôme gothique de saint Martin, symbole de la perception chrétienne de soi de la capitale, l'édification d'un mémorial en hommage aux victimes de l'Establishment catholique du premier État slovaque tout à côté du dôme, devenait une affaire délicate, avec plusieurs contrecoups idéologiques. Finalement, en 1995, après de longues négociations entre le Musée juif, soutenu par le Ministère de la Culture (étant à cette période dans le domaine d'influence du Mouvement pour une Slovaquie démocratique de V. Mečiar) et la mairie démocrate-chrétienne de Bratislava, cette affaire finit par trouver une issue et le projet du mémorial fut mis au concours. La proposition du sculpteur académique Milan Lukáč fut retenue et réalisée en 1996. Les dimensions discrètes et la réalisation esthétique non conventionnelle de sa conception (une composition en bronze de caractère tellement abstrait qu'à l'exception de l'étoile à six branches dressée à son sommet et de l'inscription «Zakhor!» sur son socle, elle peut être interprétée au gré de chacun), concilient tant les critères éthiques se rapportant à cette initiative, que les critères pratiques avancés par les conseillers municipaux, notamment, que le mémorial accomplisse également la fonction d'attraction touristique.

91 Le mémorial de l'Holocauste postcommuniste de Bratislava, résultat d'un compromis des différentes attentes, réussit par conséquent à remplir de multiples fonctions : il rend hommage aux Juifs de Slovaquie déportés et jamais revenus; il localise le siège détruit d'une communauté ancienne dont l'histoire s'entrelaçait étroitement avec celle de la ville aux trois noms et aux nombreuses identités ; il sert de point touristique et en même temps de camouflage esthétique d'un coin perdu à la périphérie de la vieille ville, au point d'intersection entre la construction fonctionnaliste du Pont Neuf et du dôme gothique de saint Martin se dressant tout près du bord des routes d'accès vers le pont.

Après l'édification du Mémorial de l'Holocauste à Bratislava à l'initiative du MCJ, la ville avait encore une dette indéniable à réparer dans le domaine de son héritage culturel juif. Il s'agissait de préserver de l'érosion totale le tombeau de Ḥatam Sofer et les 22 tombes du "district rabbinique » constituant son entourage. La communauté juive de Bratislava, sous la conduite de l'ethnologue Peter Salner, s'acquitta de l'organisation de cette tâche difficile.

Avant de décrire le processus de réalisation de cette action compliquée avançons les renseignements les plus importants sur l'histoire de ce lieu de sépulture peu conventionnel.

Lorsque le fameux rabbin orthodoxe Ḥatam Sofer mourut en 1839, il fut enterré à Bratislava (alors Pressburg), dans l'ancien cimetière juif de la ville. Ce cimetière datant de la fin du XVII ${ }^{e}$ siècle ne resta en fonction que jusqu'en 1847. Il fut détruit entre 1942 et 1943 en conséquence de la construction d'un tunnel sur la rive gauche du Danube, destiné à la défense civile. Les restes corporels des tombeaux furent exhumés et transportés par les membres de la Hevrah kaddisha $»^{74}$ de Bratislava pour être déposés dans une fosse commune près du cimetière orthodoxe juif. En dépit des déportations dévastatrices vers les centres de mort qui battaient leur plein à l'époque, la communauté juive de Bratislava réussit à négocier une solution de compromis avec le gouvernement slovaque afin de sauver du déplacement et de la destruction les 23 tombeaux des rabbins les plus éminents de ce cimetière et parmi eux, celui de Hatam Sofer. Bien que le cimetière dût céder sa place aux projets d'extension du quai de la 
rive, le district rabbinique ne fut pas concerné par ces changements. Néanmoins, comme le terrain du quai devait être rehaussé lors des travaux de construction du tunnel, la sépulture risquait d'être recouverte; on la protégea par un "sarcophage » de béton situé à environ $15 \mathrm{~cm}$ au-dessous de la surface. Elle "survécut" ainsi aux destructions de la guerre et à la barbarie culturelle du communisme. Ajoutons que la disposition souterraine inhabituelle de la sépulture n'empêchait pas les pèlerins juifs orthodoxes du monde entier de continuer à visiter ce «lieu saint» vers lequel, de surcroît, et jusqu'en 1982, l'unique accès se faisait à travers une ouverture ressemblant à une bouche d'égout située tout à côté d'un trottoir fréquenté ${ }^{75}$. Lorsqu'en 1982 la Mairie de Bratislava décida d'installer de nouveaux rails de tramway tout au long de la rive gauche du Danube, une loge en verre opaque, presque impossible à distinguer d'un arrêt de tramway quotidien, fut érigée au-dessus de l'entrée de la sépulture rabbinique. $\mathrm{Au}$ bout de quelques années, le trafic régulier des tramways directement au-dessus des tombeaux eut des conséquences néfastes sur les pierres tombales en grès qui commencèrent à se déliter. En 1999, quand une action internationale de préservation fut entreprise en faveur de la sépulture, avec l'agrément des représentants de la Mairie de Bratislava pour déplacer les rails et donner place à un mémorial en hommage à Ḥatam Sofer, les pierres tombales étaient déjà dans un état critique.

Ce n'est que grâce à l'importance religieuse incontestable de Ḥatam Sofer pour l'orthodoxie juive du monde entier que les coûts énormes de cette action purent être couverts sans intervention de fonds publics officiels slovaques. À part les donateurs privés, les principaux sponsors du projet étaient : Le Rabbinat orthodoxe de Jérusalem (Beth Din Zedek), le Comité pour la préservation des tombeaux de Hatam Sofer et des Guéonim de Presbourg (Va'ad le-shmirat kever Hatam Sofer Ugeonai), siégeant à New York et l'Association pour la préservation des cimetières juifs en Europe (Atra Kaddisha) ${ }^{76}$.

La mission de ces comités religieux de l'extérieur était, entre autres, de veiller à ce que toutes les prescriptions religieuses liées au contact avec le sol d'un cimetière juif soient observées au cours des travaux, et ce, dans les moindres détails. Comme dans le judaïsme, la nature des prescriptions religieuses consiste en des antagonismes conceptuels assortis de leur discussion infinie, la contribution de ces comités à l'avancement des travaux n'était pas toujours productive. Afin d'éviter que ne se manifeste par la suite une concurrence possible de critères et d'opinions de la part des différentes fractions religieuses concernées par la naissance du Mémorial, la communauté juive de Bratislava choisit d'engager un artiste slovaque non juif pour la réalisation artistique du projet.

L'architecte académique Martin Kvasnica, lui-même catholique pratiquant, se révéla être l'artiste adéquat pour ce défi peu commun. Il parvint avec bravoure à harmoniser les solutions techniques et les idées esthétiques avec les observations strictement religieuses de la halakha ${ }^{77}$. Son ingéniosité professionnelle se manifesta par exemple dans le fait qu'il réussit à construire un monument au centre d'un cimetière de façon à ce qu'il ne fasse pas partie de ce cimetière; il trouva également une solution pour rendre ce lieu accessible aux Cohen à qui, en tant que descendants des prêtres du Temple de Jérusalem, il n'est pas permis d'entrer dans l'enceinte d'un cimetière, ${ }^{78}$ etc. Son œuvre architectonique présente un compromis emphatique entre le spirituel et le temporel. La construction, terminée en 2002, satisfaisait même aux exigences les plus contradictoires émanant des différentes autorités rabbiniques et devenait non 
seulement un lieu rappelant une époque glorieuse de l'histoire des Juifs de Bratislava, mais aussi un héritage culturel commun rapprochant les citoyens de cette ville en crise d'identité.

99 Ce qui relie les deux mémoriaux postcommunistes de notre description, en hommage aux 60000 citoyens slovaques tués et à leur héritage culturel détruit, sont les traits suivants : ils sont conçus de manière à faire partie de l'«imago loci» de la ville sans être trop démonstratifs dans leur appel à la mémoire de la société; conformément à ce principe, ils adressent leur message à la postérité d'une manière discrète et non pathétique, en faisant surtout appel au sens commun des citoyens pour un certain patriotisme local à l'égard de leur environnement, admettant le droit de cité pour tous, y compris pour les Juifs.

\section{Conclusion}

Comme il ressort de cet article, le MCJ est une institution née sur la base de compromis idéologiques sensibles, son existence est dans une grande mesure instrumentalisée par la volonté des pouvoirs publics slovaques. Son fonctionnement et son développement général reflètent ainsi de façon perceptible l'évolution des conditions sociales dans la jeune République slovaque.

101 Sans renoncer à un point de vue critique sur le mode d'interprétation, idéologiquement conformiste du MCJ, de l'histoire moderne des Juifs de Slovaquie, il est incontestable que le Musée a réussi à dépasser son statut prédestiné de "lieu de mémoire " et à devenir, en dépit de son autonomie organisationnelle, minime en tant qu'institution d'état, un lieu d'engagement social.

Pour conclure sur le rôle social que peut remplir un musée juif dans une société postcommuniste, citons Pavol MešŤan qui, dans un entretien pour le magazine Shalom, s'expliquait ainsi au sujet de sa tâche professionnelle :

Pour moi, il s'agit avant tout de lutter contre l'ignorance qui provoque et entretient

l'antisémitisme ${ }^{79}$.

103 Il dépend du développement démocratique de la société slovaque que cette tâche soit, ne serait-ce qu'en arrière-plan, poursuivie à l'avenir ${ }^{80}$.

\section{NOTES}

1. Fondé en 1938 comme héritier idéologique du Parti du peuple slovaque, parti nationaliste et antisémite guidé par le prêtre catholique Andrej Hlinka.

2. Après le $1^{\mathrm{er}}$ arbitrage de Vienne le 2 novembre 1938, les parties sud de la Slovaquie et de l'Ukraine carpatique furent rendues à la Hongrie; elles représentaient une partie de ses territoires perdus en 1920 comme conséquence du Traité de Trianon.

3. Les Juifs de Slovaquie étaient de nationalité slovaque ou hongroise ou allemande.

4. La Hongrie a refusé d'accueillir ces Juifs déportés qui se retrouvaient ainsi, en pleine froidure de novembre, dans une zone déserte, sans vêtements chauds, sans aménagements sanitaires ni 
soins médicaux. Ils restèrent dans ces conditions inhumaines jusqu'en décembre 1938 où ils furent autorisés à rentrer en territoire slovaque. Voir Eduard Nižňanský : Židovská komunita na Slovensku medzi československou parlamentnou demokraciou a Slovenským štátom v stredoeurópskom kontexte [La communauté juive en Slovaquie entre la démocratie parlementaire tchécoslovaque et l'État Slovaque, dans le contexte central-européen], Universum, Prešov 1999, p. 261.

5. Terme emprunté à Raul Hilberg. Voir Raul Hilberg : La destruction des Juifs d'Europe. Traduit de l'anglais par Marie-France de Paloméra et André Charpentier, Gallimard, Paris, 1996, p. 621.

6. Notre analyse concerne la période électorale entre 1992 et 1998.

7. Cette abréviation sera utilisée tout au long du texte.

8. Eugen Bárkány (1885-1967). Sa collection qui comprenait des objets de culte de 35 différentes communautés juives de Slovaquie fut après la fermeture forcée du Musée juif en 1938, remise aux archives départementales de Košice (ville de Slovaquie orientale). Elle échappa ainsi à la destruction pendant la Deuxième Guerre mondiale. Après 1945, 279 objets de cette collection furent remis aux dépôts du Musée juif de Prague d'où ils furent intégralement restitués au Musée National slovaque après la partition de la Tchécoslovaquie en 1993. Ils constituent aujourd'hui la base de l'exposition permanente du Musée juif à Prešov, réouvert en 1994. Voir Volavková Hana : Dějiny Židovského muzea v Praze [L’Histoire du Musée juif de Prague], Artia, Praha, 1968, p. 83.

9. Ils rappelaient l'épisode de la « crise des Sudètes » à la suite duquel les territoires habités par la minorité allemande de Bohême étaient « rendus » à l'Allemagne, et annulaient ainsi la dernière révision territoriale des Accords de Versailles.

10. D'après le recensement de la population de 1992, il y a moins de 6000 Allemands carpatiques en Slovaquie, bien que leur nombre non officiel varie de 15000 à 20000 . Voir István Lanstyák : À magyar nyelv Szlovákiában [La langue hongroise en Slovaquie], Osiris-Kalligramm, BudapestPozsony, 2000, p. 38.

11. Roland Süssmann (dans la rédaction de) : "Tradition et patrimoine », in : Slovaquie, "Shalom Magazine ", no.44, octobre 2005, p. 1.

12. Anecdote citée dans le cadre de l'exposé de Gennady Estraikh, lors du IIIe symposium sur les études yiddish en Allemagne, à Düsseldorf en août 2000.

13. Il s'agit particulièrement des atteintes visant à saper l'économie des théâtres qui adoptaient une attitude critique envers l'Établissement politique du pays, et à restreindre le tirage du quotidien libéral « SME ».

14. Pavol MešŤan : Antisemitismus v politickom vývoji Slovenska (1989-1992) [L'antisémitisme dans le développement politique de la Slovaquie (1989-1992)], publication du Ministère de la Culture de Slovaquie, Bratislava, 1999, pp. 37-43.

15. Il s'agit du Mouvement pour une Slovaquie démocratique et du Parti National Slovaque.

16. Le Ministère siégeait dans un immeuble austère de style fonctionnaliste, aux dimensions cubiques d'une immense usine. Cette ambiance de « lieu de production » était particulièrement perceptible lorsqu'on se tenait à l'entrée principale du bâtiment, face au spectacle des ascenseurs du type "pater noster» qui, toute la journée, montaient et descendaient en un parcours ininterrompu d'une monotonie spectrale.

17. J'ai puisé mes informations pour ce chapitre des ouvrages suivantes : Eugen Bárkány -L’udovít Dojč : Židovské náboženské obce na Slovensku [Les communautés juives de la Slovaquie], Vesna, Bratislava, 1991. Robert Büchler : Múzeum židovskej kultúry [Le musée de la culture juive], Judaica Slovaca, Bratislava, 1995. Hugo Gold: Die Juden und die Judengemeinde Bratislava in Vergangenheit und Gegenwart, Jüdischer Buchverlag, Brünn, 1932.

18. De la dynastie des Arpad. André III de Hongrie, né en 1265, régna du 10 juillet 1290 jusqu'à sa mort (à Buda) le 14 janvier 1301.

19. En reconnaissance de leur contribution importante à la vie économique de la ville, les Juifs de Bratislava furent, en 1520 dispensés par Louis II de Hongrie (de la dynastie Jagellon) de 
l'obligation de porter le costume consistant en un chapeau pointu et en un manteau rouge sur lequel était cousu un cercle jaune, la rouelle.

20. Le 29 août 1526, Louis II fut vaincu par Süleyman II et les Turcs s'emparèrent de Buda, la capitale. Le pays fut divisé en deux : Ferdinand de Habsbourg régna sur la moitié occidentale et János Zápolyai sur la moitié orientale.

21. Entre 1563 et 1830, onze rois et huit reines de la maison des Habsbourg furent couronnés sous le Dôme de saint Martin de Bratislava.

22. Voir la note 133.

23. Le nombre des Juifs installés au Schlossberg augmenta avec l'arrivée des réfugiés juifs de Vienne après leur expulsion en 1699-70 par Léopold II.

24. Importé par les réfugiés juifs de Moravie qui avaient dû quitter leur pays en conséquence d'un édit de la Diète de Moravie de 1650. D'après cet édit, les Juifs n'avaient le droit de résider que dans les lieux où ils vivaient déjà avant le déclenchement de la guerre de Trente Ans, en 1618.

25. En 1782, Joseph II promulgua un Édit de Tolérance émancipant les Juifs de l'Empire Germanique de même que les chrétiens non catholiques.

26. Par exemple les Esterházy, les Forgách, les Erdődy, etc.

27. Néologie : appellation non officielle du mouvement de la Réforme juive au XIX ${ }^{\mathrm{e}}$ siècle en Hongrie.

28. Peter Salner: "Ethnic Polarisation in an Ethnically Homogenous Town", Czech Sociological Review, Prague, no.9, février 2001, p. 241.

29. Pavel Dvořák: Bratislava - podhradie (Svedectvo pohL'adníc) [Bratislava au-dessous du château (Le témoignage des cartes postales)], Rak, Bratislava, 1991, non paginé.

30. Ivan Karp - Steven D. Lavine: Exhibiting cultures, Smithsonian Institution Press, Washington, 1990, pp. 42-56.

31. De son vrai nom, Moses Schreiber, rabbin de la communauté juive de Pressburg (Bratislava) de 1806 à 1839. Il fut l'adversaire intransigeant du mouvement de la Réforme de Moses Mendelssohn et lutta sans compromis contre toute dérive de la Halakha. Ses commentaires de la Tora servent jusqu'à aujourd'hui d'autorité incontestable pour l'orthodoxie juive mondiale. Les descendants de Ḥatam Sofer ont occupé le poste du rabbin de Pressburg pendant trois générations, jusqu'en 1939. Le dernier descendant en ligne directe de la dynastie "Sofer» vit aujourd'hui en Israël.

32. Institution juive traditionnelle d'enseignement supérieur.

33. À Bratislava (en allemand Pressburg), la littérature religieuse en yiddish et en hébreu fut imprimée dès 1789 , jusqu'aux années $30 \mathrm{du} \mathrm{XX}^{\mathrm{e}}$ siècle.

34. R. Hilberg : La destruction des Juifs d'Europe, p. 629.

35. Boîtes à bessamim, c'est-à-dire boîtes à parfum utilisées à l'occasion de la cérémonie finale du sabbat.

36. R. Süssmann : «Tradition et patrimoine », in : Slovaquie, p. 1.

37. Robert Büchler: Múzeum židovskej kultúry [Le musée de la culture juive], Judaica Slovaca, Bratislava, 1995, p. 13.

38. R. Hilberg : La destruction des Juifs d'Europe, p. 642.

39. Président de la République tchécoslovaque de 1935 jusqu'à son exil pendant la Deuxième Guerre mondiale, puis dans une deuxième période entre 1945 et 1948.

40. Ivan Kamenec: Po stopách tragédie [Sur les traces d'une tragédie], Archa, Bratislava, 1991, p. 262.

41. "Vienne la nation slovaque entière se joindre à moi dans ma joie et transmettre à Votre Excellence l'espérance qu'un succès béni similaire accompagne la lutte hérö̈que du grand Empire Germain pour l'existence et l'honneur de sa nation et pour la protection de la culture 
européenne. » Voir J. S. Conway: “The Churches, the Slovak State and the Jews (1939-1945)”, Slavonic and East European Review, 1974, p. 110.

42. I. Kamenec: Po stopách tragédie, p. 62.

43. À côté de la minorité hongroise représentée depuis 1936 au Parlement tchécoslovaque par le Parti hongrois unifié (Egyesült Magyar Párt) et de la minorité allemande représentée par le Parti des Allemands des Sudètes (Sudentendeutsche Partei) fondé en 1935, les Juifs eurent également leur représentation politique. Le Parti juif (Židovská Strana), parti d'orientation sioniste, fonctionna entre 1919 et 1938. Pendant les élections de 1929, il avait reçu un soutien suffisant - en coalition avec le Parti minoritaire polonais - pour pouvoir obtenir deux députés au Parlement tchécoslovaque. Après que la Slovaquie eut acquis son autonomie le 6 octobre 1938 et que le Parti populaire de Hlinka eut pris le contrôle au Parlement selon le principe « Une nation, un parti », le Parti juif fut, entre autres partis (le Parti communiste, le Parti social-démocrate et le Parti travailliste socialiste-sioniste unifié), interdit par l'État. En ce qui concerne la répartition politique des Allemands carpatiques de Slovaquie, leur aile radicale fusionna dès 1935 avec le Parti des Allemands des Sudètes, pronazis, et leur aile modérée souhaitant la restauration de l'Empire austro-hongrois, avec le Parti hongrois unifié. Voir Livia Rothkirchen : "Slovakia", in : Geoffrey Wigoder (sous la direction de) : Encyclopaedia Judaica, I-XVI, Jérusalem, 1997, (Cd-rom).

44. Zoltán Balassa : "A felvidéki Magyarság mártírja » [Un martyr de la Haute-Hongrie], «Erdélyi Napló » (quotidien hongrois de Transylvanie), Nagyvárad, 30 juin 1998, p. 1.

45. I. Kamenec: Po stopách tragédie, p. 63.

46. En conséquence de l'arbitrage de Vienne, la Slovaquie a perdu $10423 \mathrm{~km}^{2}$ de son territoire et 859855 de ses habitants (276 287 Slovaques, 505808 Hongrois, 26181 Juifs, 8967 Allemands, 1829 Ruthènes). Voir Eduard Nižňanský: Židovská komunita na Slovensku medzi československou parlamentnou demokraciou a Slovenským štátom $v$ stredoeurópskom kontexte [La communauté juive dans la Slovaquie entre la démocratie parlementaire tchécoslovaque et l'État Slovaque, dans le contexte central-européen], Universum, Prešov, 1999, p. 32.

47. Zoltán Balassa : «Száz éve született Esterházy János » [Il y a cent ans, naissait János Esterházy], Honismeret, $\mathrm{n}^{\circ}$ 29, mars 2001, p. 5.

48. Ibid. p. 5 .

49. Ibid. pp. 7-8.

50. Gábor Szent-Ivány: Graf János Esterházy, Führer der ungarischen Minderheit und das Schicksal der Ungarn in der Tschechoslovakei/Slowakei nach dem Ersten Weltkrieg, Böhlau Verlag, Wien-KölnWeimar, 1995, p. 225. Dans le prologue de l'ouvrage cité ci-dessus, Otto von Habsburg, député du Parlement européen, caractérisait J. Esterházy ainsi : »Er hatte schon früh die ideologische, rechtlose und menschenverachtende Gleichheit des Nationalsozialismus mit dem Kommunismus erkannt und sich somit beide zum Feind gemacht. Die Rache des Totalitarismus blieb auch nicht aus. Esterházy - der Anti-Nazi - wurde von der Beneš-Regierung und den Sowiets als Faschist verurteilt und starb unschuldig nach vielen Jahren im Gefängnis. Die Russen haben ihn und seine Leidensgenossen vor kurzem rehabilitiert, seitens der Slowakei steht dieser Schritt noch aus.«

51. P. MešŤan : Antisemitismus, p. 12.

52. La Slovaquie devint partie intégrante de la République Tchécoslovaque après avoir reçu son statut autonome le 28 octobre 1918, avec à sa tête son président fondateur Tomáš G. Masaryk.

53. Le royaume de Grande-Moravie fondé vers 830 par des tribus slaves (et qui à un moment donné comprenait la Slovaquie occidentale), fut envahi par les Magyars à la fin du IX ${ }^{\mathrm{e}}$ siècle.

54. Peter Bugge: "The Making of a Slovak City: The Czechoslovak Renaming of Pressburg/ Pozsony/Prešporok, 1918-19”, Austrian History Yearbook, no 35, 2004, p. 219.

55. La signification étymologique du terme "Bratislava» est "gloire aux frères [slaves]». Elle renvoie aux formes Wratislaburg, Bretislaburg, Breslauburg, Presburg, se trouvant dans des sources germaniques médiévales. 
56. J'utiliserai cette dénomination pour la période avant 1919, et celle de Bratislava pour la période après 1919.

57. L'Autriche et la Hongrie s'allièrent en un État dualiste où ils eurent des gouvernements et des parlements séparés, mais ils avaient le même roi, et les Affaires étrangères étaient dirigées en commun. Après la ratification de "l'Entente » en 1867, le Parlement hongrois avait également promulgué une loi accordant aux Juifs des droits égaux à ceux des autres citoyens du pays. Cet acte politique eut un impact important sur l'amélioration de la situation légale des Juifs dans le Royaume hongrois, ce qui explique leur durable loyauté vis-à-vis de la Hongrie, loyauté qui se refléta également dans leur attachement tenace à la nationalité hongroise.

58. Pour comparer : en 1890 Pressburg avait 50546 habitants dont 59,9\% étaient Allemands, 19,9 \% Hongrois, 16,6 \% Slovaques et 3,6 \% d'une autre nationalité. En 1910, lorsque la population de la ville augmenta et compta 78223 habitants, les Allemands constituaient $41,9 \%$ de la population, les Hongrois 40,5\%, les Slovaques $14,9 \%$ et les autres nationalités 2,7\%. Voir Peter Salner : "Ethnic Polarisation in an Ethnically Homogenous Town", Czech Sociological Review, no9, Prague, février 2001, p. 241.

59. En 1900, la ville avait 61537 habitants, dont 6368 Juifs, constituant ainsi 10,34\% de la population. En 1910 le nombre des Juifs avait augmenté et était passé à 8207 , répondant similairement à 10,49\%_de la population. Voir Hugo Gold: Die Juden und die Judengemeinde Bratislava in Vergangenheit und Gegenwart, Jüdischer Buchverlag, Brünn, 1932, p. 172.

60. Lors du recensement de la population en 1919, Bratislava comptait 83223 habitants répartis en 24577 citoyens de nationalité hongroise, 26964 de nationalité tchécoslovaque, 30221 de nationalité allemande et 1461 d'une autre nationalité. Voir P. Bugge: "The Making of a Slovak City: The Czechoslovak Renaming of Pressburg/Pozsony/Prešporok, 1918-19”, p. 226. Ces données statistiques sont néanmoins très subjectives, étant donné les circonstances politiques tendues en arrière-plan. La majorité des 26964 habitants qui se déclarèrent de nationalité tchécoslovaque, étaient probablement des Slovaques constituant en moyenne $15 \%$ de la population de la ville, mais qui pouvaient également se répartir dans les cadres de la nationalité allemande et hongroise. Le reste était vraisemblablement constitué des Juifs cherchant une sécurité existentielle dans les conditions politiques nouvelles.

61. En 1921, Bratislava comptait 93180 habitants dont 37038 étaient de nationalité tchécoslovaque, 25837 de nationalité allemande, 20731 de nationalité hongroise, 10973 Juifs de religion israélite dont seulement 3758 se disaient de nationalité juive. Voir Hugo Gold: Die Juden und die Judengemeinde Bratislava in Vergangenheit und Gegenwart, pp. 172-173.

62. En 1927 Bratislava avait 133164 habitants dont 12852 étaient Juifs de religion israélite, soit 9,5\% de la population ; 5127 d'entre eux se disaient de nationalité juive, soit 39,89\% du nombre total des Juifs. Ibid. p. 173.

63. En 1930, Bratislava avait 14822 habitants juifs, mais seulement 4747 (5597 d'après l'Encyclopedia Judaica) s'étaient déclarés de nationalité juive. Voir P. Salner : "Evolution of Jewish Identity in Slovakia", in: "Ethnic Studies and the Urbanized Space in Social Anthropological Reflections", Prague Occasional Papers in Ethnology no5, 1998, p. 63. La composition ethnique du reste de la population comprenait $29,8 \%$ de Slovaques, $28,1 \%$ d'Allemands, $16,2 \%$ de Hongrois, $25,9 \%$ d'autres (cette catégorie englobe aussi les Tchèques qui à partir de 1930 furent enregistrés séparément des Slovaques). Voir P. Salner : Ethnic Polarisation in an Ethnically Homogenous Town, p. 241.

64. R. Büchler : Múzeum židovskej kultúry [Le musée de la culture juive], p. 13. Les $12 \%$ manquants, que Büchler ne précise pas, se répartissaient apparemment entre l'appartenance à la religion israélite et à la nationalité allemande.

65. Les convertis au christianisme définis «Juifs » en 1941, n'avaient pas encore été dénombrés comme Juifs dans le recensement de 1940. Voir R. Hilberg : La destruction des Juifs d'Europe, p. 623. 66. Voir l'introduction historique (chapitre 0.) 
67. La capitale de Slovaquie comptait une population juive de 15000 personnes, mais seules 10000 d'entre elles durent partir. Les 5000 autres - détenteurs de permis de travail, employés de l'État, chefs d'entreprise et membres de professions libérales (avec leurs familles) - furent autorisés à rester. Ibid. p. 628.

68. En 1950, Bratislava avait 170000 habitants ; 90,2 \% se déclarèrent Slovaques, 3,5 \% Hongrois, $0,6 \%$ Allemands et 5,7 \% en tant qu'autres (dans leur majorité probablement Tchèques). En 1970, Bratislava avait 290000 habitants; $91,5 \%$ se déclarèrent Slovaques, 3,5\% Hongrois, 0,4\% Allemands et 4,6 \% en tant qu'autres. Voir P. Salner : Ethnic Polarisation in an Ethnically Homogenous Town, p. 241. Entre 1950 et 1970, la population de Bratislava augmenta de 120000 habitants (soit un peu plus d'un tiers) ; cet accroissement résultait d'une politique dite "de sédimentation ", conduite par le régime communiste et qui, afin de rompre la solidarité des restes de la bourgeoisie locale, consistait à homogénéiser la structure ethnique de la ville en procédant à des apports massifs de Slovaques de souche venus des régions environnantes et que l'on installait dans la ville. Cette population qui n'avait aucune attache historique avec Bratislava, accepta pour cette raison et sans protestation la soi-disant «tchécoslovaquisation" des espaces publics, nommément, la vandalisation par l'État des monuments historiques ayant un rapport avec les identités historiques antérieures de la ville et cela, dans le but de supprimer la mémoire historique de ses habitants.

69. En 1990, Bratislava comptait 442000 habitants dont 90,4\% s'étaient déclarés Slovaques, 5,3\% Hongrois, 0,2 \% Allemands et 4,1\% autres. Comme résultat de la politique d'assimilation de l'État pendant 70 ans, ces chiffres reflètent la composition ethnique réelle de la ville.

70. R. Süssmann : «Tradition et patrimoine », in : Slovaquie, p. 3.

71. Ibid. p. 1.

72. E. Bárkány - L'. Dojč : Židovské náboženské obce na Slovensku, p. 186.

73. Par ex., à Bratislava, Nitra, Trnava, Lučenec, Žilina, Rymavská Sobota. Voir Soňa Kovačevičová : Príspevok $k$ dejinám a kultúre židovských náboženských obcí na Slovensku [Contribution à l'Histoire et à la culture des communautés juives en Slovaquie], in : L’udovít Harakšim (sous la direction de) : Národnosti na Slovensku [Les nationalités en Slovaquie], Veda, 1993, p. 124.

74. Société funéraire juive dont la fonction principale était de préparer le corps du défunt pour l'enterrement en accord avec les traditions juives. Outre cette fonction, les membres de cette société s'acquittaient d'autres activités de charité telles que la visite aux malades, l'aide aux pauvres, etc.

75. Cet emplacement inhabituel pour une entrée de lieu de pèlerinage causait de temps en temps des situations comiques, quand des personnages d'apparence spectrale, coiffés de grands chapeaux et portant de longues papillotes, sortaient soudainement « du dessous de la terre » et terrifiaient complètement les piétons empruntant leur route quotidienne sans se douter de rien. De plus, c'était une époque où la globalisation n'avait pas encore atteint l'Europe Centrale pour déplacer les frontières d'imagination de ses citoyens communs.

76. L'attitude intransigeante de cette association illustre le cas suivant : en 2000, lors des travaux de construction d'une Caisse d'épargne à Prague, on découvrit les restes d'un cimetière juif ancien. Alors, une véhémente campagne de protestations commença, lancée par l'organisation "Atra Kaddisha », qui refusait conséquemment toute solution de compromis (par ex., enfermer les tombes dans un sarcophage de béton). Leur argument principal était que tout changement de la disposition du cimetière aurait «troublé le droit pour le libre exercice des opérations religieuses, assurées par la Déclaration européenne des droits de l'Homme". D'après les conclusions d'une expertise archéologique, le dernier enterrement avait eu lieu dans ce cimetière vers la fin du XV siècle... En fin de compte, les investisseurs furent contraints de céder aux protestations internationales et durent, à coûts renforcés, déplacer les travaux de construction. Voir Peter Salner - Martin Kvasnica : Chatam Sofer Memoriál (1762-2002), Zing Print, Bratislava, 2002, p. 91.

77. L'ensemble de lois et règlements religieux dans le Talmud. 
78. Le Mémorial fut construit sans fondations, directement à la surface du terrain. De cette façon, il «flotte » au-dessus du sol, sans être strictement parlant une part du cimetière. Outre cela, le plafond de la galerie souterraine du Mémorial est symboliquement interrompu entre l'espace des visiteurs et l'espace propre comprenant les tombes des rabbins, afin d'assurer une fois de plus que les Cohen y puissent prier sans entrer en contact direct avec le « cimetière ». M. Kvasnica surnomma cette ligne d'interruption «le séparateur des Cohen », (" kohenský separátor») qui, selon l'avis de plusieurs autorités rabbiniques, est une solution unique en son genre dans le monde entier.

79. R. Süssmann : «Tradition et patrimoine », in : Slovaquie, p. 3.

80. Aux élections parlementaires de juin 2006, après huit ans en retrait, les forces populistes et nationalistes ont de nouveau gagné. Ce tournant politique régressif peut servir d'argument renforçant la nécessité du travail pédagogique du MCJ.

\section{RÉSUMÉS}

The central idea and the purported role which organize the work of a given Jewish museum clearly refer to the issues occupying its surrounding society with the greatest intensity or, alternatively, to the theme that could have the best chance of being digested by that society. Such issues may include the thematization of anti-Semitism or of the Holocaust, or may have a cultural mediating role. To what extent can we find a reflection of the Central-European Jewry's multi-layered process of self-definition in the work of the Museum of Jewish Culture in Bratislava after 1989? Furthermore, to what extent does this process of self-definition follow the historical image conceived in the consciousness of the surrounding societies? What are the social conditions, the historical precursors and the future perspectives of these self-reflections? These are the questions to which I purport to find an answer in my article.

\section{INDEX}

\section{מילות מפתח}

היהודים בסלובקיה, ברטיסלבה, סלובקיה, מוזיאון התרבות היהודית, גיוון תרבותי,:

תרבות המיעוטים, שואה, המאה העשרים, שלוסברג, אוברלנדר, חתם סופר, יהודי הונגריה עליון Index géographique : Bratislava, Slovaquie

Keywords : Jews in Slovakia, Bratislava, Slovakia, Museum of Jewish culture, cultural Diversity, cultural minorities, Holocaust, twentieth century, Oberländer, nineteenth century, Jews of Upper Hungary, Schlossberg, Sofer Hatam (1762-1839)

Mots-clés : Juifs de Slovaquie, Musée de la culture juive, diversité culturelle, minorités culturelles, Oberländer, Juifs de Haute-Hongrie, Schlossberg, Sofer Ḥatam (1762-1839)

Index chronologique : dix-neuvième siècle, vingtième siècle, Shoah 